\section{Transfer from Long to Short Photoperiods Affects Production Efficiency of Day-neutral Rice}

\author{
K. Rachelle Goldman ${ }^{1}$ and Cary A. Mitchell ${ }^{2}$ \\ Department of Horticulture and Landscape Architecture, Purdue University, \\ West Lafayette, IN 47907-1165
}

Additional index words. Oryza sativa, advanced life-support systems, cropping efficiency, daylength, harvest index, source-sink, tillering

\begin{abstract}
The day-neutral, semidwarf rice (Oryza sativa L.) cultivar Ai-Nan-Tsao was grown in a greenhouse under summer conditions using high-pressure sodium lamps to extend the natural photoperiod. After allowing 2 weeks for germination, stand establishment, and thinning to a consistent planting density of 212 plants $/ \mathrm{m}^{2}$, stands were maintained under continuous lighting for 35 or 49 days before shifting to 8- or 12-h photoperiods until harvest 76 days after planting. Non-shifted control treatments consisting of 8-, 12-, or 24 $h$ photoperiods also were maintained throughout production. Tiller number increased as duration of exposure to continuous light increased before shifting to shorter photoperiods. However, shoot harvest index and yield efficiency rate were lower for all plants receiving continuous light than for those under the 8- or 12-h photoperiods. Stands receiving 12-h photoperiods throughout production had the highest grain yield per plant and equaled the 8-h-photoperiod control plants for the lowest tiller number per plant. As long as stands were exposed to continuous light, tiller formation continued. Shifting to shorter photoperiods late in the cropping cycle resulted in newly formed tillers that were either sterile or unable to mature grain before harvest. Late-forming tillers also suppressed yield of grain in earlyforming tillers, presumably by competing for photosynthate or for remobilized assimilate during senescence. Stands receiving 12-h photoperiods throughout production not only produced the highest grain yield at harvest but had the highest shoot harvest index, which is important for resource-recovery strategies in advanced life-support systems proposed for space.
\end{abstract}

Long-term manned space flight and lunar or Mars bases will be feasible only if lifesupport consumables such as oxygen, water, and food are generated on site. Resupply from Earth would be prohibitively expensive, making recycling of renewable resources a necessary alternative (Schwartzkopf, 1992). In future space life-support systems, renewable resources will be cycled through a combination of biological and physicochemical processors (Olson et al., 1988). Higher plants may constitute an important component of such advanced life-support systems (ALS). During photosynthesis, crop plants remove $\mathrm{CO}_{2}$ while replenishing $\mathrm{O}_{2}$ and producing edible biomass. They also transpire potentially potable water (Corey and Wheeler, 1992). Crop spe-

Received for publication 8 Sept. 1998. Accepted for publication 20 Jan. 1999. Journal paper no. 15758 of the Purdue Univ. Agricultural Research Project. Research supported in part by NASA grant NAGW2329. We thank Kathie Pasquetti and Jason Rhoades for their technical assistance in all aspects of this study. The cost of publishing this paper was defrayed in part by the payment of page charges. Under postal regulations, this paper therefore must be hereby marked advertisement solely to indicate this fact.

${ }^{1}$ Current address: Texas A\&M Univ., Dept. of Horticultural Sciences, College Station, TX 77843 2133.

${ }^{2}$ To whom reprint requests should be addressed. cies selected for ALS should have high nutritional value and be easily processed into a variety of palatable food products. They also should adapt readily to hydroponic culture and be high yielding (Mitchell, 1994).

Rice is a candidate cereal species for ALS inclusion because its grain has a bland flavor that makes its incorporation into a variety of food products feasible, contains at least $7.5 \%$ protein, and the plant is naturally adaptable to hydroponic culture (Hoff et al., 1982). Photoperiod manipulation studies with rice have been limited because many varieties initiate flowers only under short days (Vergara et al., 1969). Extending the natural photoperiod would not be expected to enhance grain yield because plants would remain vegetative. However, selective breeding of photoperiodinsensitive cultivars should permit the manipulation of daylength without delaying flowering or grain maturation. In the field, the grower is limited to natural daylengths, but in controlled environments daylength extension with enhanced carbon assimilation is feasible. Extended photoperiods increased tuber yield of day-neutral potatoes, but the longest photoperiod tested did not produce the highest yield (Wheeler and Tibbitts, 1986).

In designing ALS for space destinations, inedible biomass produced, length of the cropping cycle, and total growth volume occupied are among the production penalties to be weighed in selecting cropping protocols. While not of concern for field production on Earth, the energetic cost of photosynthetically active radiation $(P A R)$ to grow crops and to recycle inedible biomass within closed habitats in space, combined with the time and volume necessary to grow crops, is potentially limiting to the bioregenerative component of ALS sustainability. Therefore, a yield-efficiency rate (YER) for grain yield, expressed as $\mathrm{g} \cdot \mathrm{m}^{-3}$ shoot volume per day per $\mathrm{g}$ of inedible shoot weight, was developed to evaluate edible yield in terms of the penalties of cropping time, volume, and nonedible biomass produced, all within a single parameter (Volk and Mitchell, 1995). Other productivity parameters used to evaluate photoperiod-shift treatments in this study included shoot harvest index (SHI): edible dry weight $(\mathrm{g})$ of grain/total shoot dry weight $(\mathrm{g})$; edible yield rate of grain (EYR): $\mathrm{g} \cdot \mathrm{m}^{-2} \cdot \mathrm{d}^{-1}$; and tiller density: tiller no. $/ \mathrm{m}^{2}$.

Volk and Mitchell (1995) reported that the southern Chinese semidwarf rice cultivar AiNan-Tsao was insensitive to photoperiod for flowering, yet was high yielding. Extending daylength with low-wattage incandescent lamps did not further enhance grain yield because the low photosynthetic photon flux $(P P F)$ daylength extension provided a photoperiodic but not a photosynthetic enhancement effect. Growing plants initially under short photoperiods, then transferring them to long days using high-pressure sodium (HPS) lamps at different stages of the cropping cycle, also did not increase yield. Inedible biomass increased, but without an equal increase in grain yield, even though tillering was enhanced by long days (Volk and Mitchell, 1995).

In the present investigation, we took the reciprocal approach of growing this day-neutral rice cultivar on long days extended with $P A R$ in an effort to promote early tillering, but then shifted plants to shorter photoperiods to shut off late tiller production. This tillering pattern should produce grain heads early in the cropping cycle that will fill completely because they would not be competing with tillers forming late in the cycle. Various yield and productivity parameters relevant to ALS requirements were used to compare long- to short-day shifted rice stands with those maintained on various constant photoperiods throughout crop production.

\section{Materials and Methods}

Semidwarf, day-neutral rice, cv. Ai-NanTsao, was grown in a greenhouse during the summer at a density of 15 plants per 19-L pot (212 plants $/ \mathrm{m}^{2}$ of pot area). Containers were lined with punctured plastic bags and filled with a growth medium consisting of 2 peat : 2 perlite : 1 topsoil (by volume) enriched with $9.6 \mathrm{~kg} \mathrm{FeSO}{ }_{4} \cdot \mathrm{m}^{-3}$. Automatic fertigation delivered nutrient solution containing $\mathrm{N}, \mathrm{K}$, and $\mathrm{P}\left(200,200\right.$, and $80 \mathrm{mg} \cdot \mathrm{L}^{-1}$, respectively) to each pot via dribble rings for $10 \mathrm{~min}$ twice daily. This fertigation protocol was sufficient to permit excess drainage of nutrient solution from the bottom of each container at each watering.

Six $75-\mathrm{ft}^{2}\left(6.97 \mathrm{~m}^{2}\right)$ benches each were 
divided into thirds, providing a total of 18 equal sections of $2.32 \mathrm{~m}^{2}$. Each section held eight randomly allocated pots. Only 14 of the 18 sections were utilized, as that was sufficient for each treatment or control photoperiod to be randomly assigned to two sections. This design allowed for concomitant duplication of treatments. At the latitude of this study (lat. $\approx 40^{\circ} \mathrm{N}$ ), natural daylength during summer is longer than $12 \mathrm{~h}$ (and up to $14.75 \mathrm{~h}$ ). To ensure an 8- or 12-h photoperiod, black shadecloth was pulled over appropriate bench sections at 1630 and $2030 \mathrm{HR}$, and was removed at 0730 HR. Sections requiring 24-h photoperiods were left uncovered and irradiated with HPS lamps, providing $350 \mu \mathrm{mol} \cdot \mathrm{m}^{-2} \cdot \mathrm{s}^{-1} \mathrm{PPF}$ from 2030 to $0730 \mathrm{HR}$. After continuous light treatment for 35 or $49 \mathrm{~d}$ using HPS lamps to extend natural daylength, sections receiving a photoperiod shift were placed under 8- or 12-h photoperiods by pulling black shadecloth. Control groups of 24-, 12-, or 8-h photoperiods were maintained throughout the experiment.

Average temperatures were $35 \pm 4{ }^{\circ} \mathrm{C}$ day/ $24 \pm 3^{\circ} \mathrm{C}$ night. Canopies within each pot were contained within 70 -cm-tall cylindrical wire cages. Germinating seeds and seedlings were grown under ambient greenhouse conditions for $15 \mathrm{~d}$ before initiating photoperiod-treatment combinations that lasted a total of $61 \mathrm{~d}$. All plants were harvested $76 \mathrm{~d}$ after seeding. Canopy height, grain yield, inedible shoot biomass, and tillers per plant were measured for each canopy. Oven dry weights (after $4 \mathrm{~d}$ at $45{ }^{\circ} \mathrm{C}$, forced air) were taken on all shoot biomass except grain. Root biomass could not be reliably recovered from the medium for accurate measurement. Analysis of variance was performed for the productivity parameters, and significance was tested for both treatment times within photoperiods and for photoperiods within treatment times according to Tukey's $\omega$ procedure.

\section{Results}

'Ai-Nan-Tsao' rice plants began to flower on day 45 regardless of photoperiod. Tiller production increased gradually as the number of days under continuous light increased before shifting to 8- or 12-h photoperiods (Table $1)$. Effects on tiller production of 8- or 12-h photoperiods following a continuous light pretreatment were insignificant. However, both SHI and YER were reduced by any length of exposure to continuous light compared with 8or 12-h photoperiod controls. Stand height of this semidwarf rice cultivar ranged from 50 to $62 \mathrm{~cm}$ above soil line and did not vary with light treatment. For plants exposed to 8-h photoperiods after any continuous light pretreatment, tiller number, but not grain yield, increased significantly with increasing exposure to continuous light. Because leaf and stem tissue mass was restricted by continuous $8-\mathrm{h}$ photoperiods, 8-h controls had the second highest SHI and YER values (0.56 and 0.37, respectively). For plants shifted from continuous light to 12-h photoperiods, grain yield per plant was constant despite increasing pretreatment exposure to continuous light, whereas inedible biomass and tiller number did increase with pretreatment. Grain yield of plants on continuous 12 -h photoperiods was higher than that of plants on continuous 8-h photoperiods. Plants under continuous light throughout the cropping cycle produced more inedible biomass than did those exposed to continuous light for shorter periods of time. They also produced the second highest grain yield and EYR achieved, despite having to support lateforming tillers. However, those late tillers either developed no flowering panicles or contained immature grain at harvest and just added to the inedible biomass burden of the crop. Exposure to continuous light lowered SHI to 0.42 and YER to 0.22 , the second lowest values produced. The 8 - and 12-h control plants produced fewer tillers than did plants in any other treatment. The 12-h controls also produced the highest amount of grain per plant. The relative lack of inedible biomass production (in the form of infertile tillers), combined with high grain production for the 12-h control plants, resulted in the highest values obtained for SHI (0.61), YER (0.44), and EYR (28.36).

\section{Discussion}

The productivity of cereals can be expressed in various useful ways, including tillers per unit area, filled grains per tiller, and weight per grain (Green, 1984). Unfortunately, the amount of filled grain tends to decrease as tiller density increases (Gravois and Helms, 1992). Wallace et al. (1993) included days to maturity as another productivity indicator. Cropping time is very important to ALS for many reasons, but particularly because it will directly affect the total energy required to produce crops within a closed, recycling environment.

In the present study, exposing 'Ai-NanTsao' rice plants to continuous PAR caused vigorous tillering. However, high tillering can be detrimental to grain yield because tillers forming late in a cropping cycle become potential competitors for grainfill with early- initiated tillers (Fagade and DeDatta, 1971). Such was the case in the present study. As time of exposure to continuous light increased before shifting to 8- or 12-h photoperiods for the remainder of the cropping cycle, production of inedible biomass, in the form of additional tillers, increased. However, this increase in tillers was without concomitant increase in grain production. When shifted from continuous light to 8- or 12-h photoperiods, tillering slowed, but these stands required more fixed carbon to support the additional tiller biomass that already had formed than did either the 8$\mathrm{h}$ or 12-h controls. The drain of newly elaborated photosynthate and/or remobilized assimilate to late-forming tillers limited grainfill and decreased SHI and YER.

Tillering of cereal crops is influenced by multiple environmental factors, including light, nutrition, and atmospheric composition. Unfortunately, cereals tend to produce more tillers than they can support, leading to tiller death without complete panicle development (Green, 1984). In addition, tillers forming late in a cropping cycle compete with earlier-forming tillers as sinks for photosynthate. This competition reduces overall panicle weight, increases the number of sterile tillers at harvest time, and increases time to grain ripening (Fagade and DeDatta, 1971). Considering the crucial role tillering plays in yield determination and the detrimental consequences of producing excess inedible biomass within ALS, devising means of manipulating tiller density without reducing grain production per unit area or shoot harvest index would benefit ALS cropping-system design.

Low PAR irradiance (15-20 klx) reduced rice yield by decreasing the number and size of individual rice grains (Janardhan et al., 1979). It also decreased overall dry-matter production and harvest index by increasing sterility (Nayak and Murty, 1980). On the other hand, higher $P A R$ irradiance $(60 \mathrm{kl})$ increased spikelet production (Janardhan and Murty, 1979). Since photosynthate stored in the stems of rice plants is remobilized and translocated into panicles during grainfill (Green, 1984), we

Table 1. Harvest parameters of 'Ai-Nan-Tsao' rice plants grown under continuous light (24-h photoperiods) for 35 or $49 \mathrm{~d}$ before being shifted to 8- or 12-h photoperiods, or maintained under 8-, 12-, or 24-h photoperiods throughout the 61-d experiment.

\begin{tabular}{|c|c|c|c|c|c|c|c|}
\hline \multicolumn{2}{|c|}{ Photoperiod/time } & $\begin{array}{c}\text { Tillers/ } \\
\text { plant } \\
\text { (no.) }\end{array}$ & $\begin{array}{l}\text { Inedible } \\
\text { biomass } \\
\text { (g/plant) }\end{array}$ & $\begin{array}{c}\text { Grain } \\
\text { biomass } \\
\text { (g/plant) }\end{array}$ & $\begin{array}{l}\text { Shoot } \\
\text { harvest } \\
\text { index }^{z}\end{array}$ & $\begin{array}{c}\text { Edible } \\
\text { yield } \\
\text { rate }^{\mathrm{y}}\end{array}$ & $\begin{array}{c}\text { Yield } \\
\text { efficiency } \\
\text { rate }^{\mathrm{x}}\end{array}$ \\
\hline 8 & 61 & $9.06 \mathrm{a}^{\mathrm{w}}$ & $5.61 \mathrm{a}$ & $7.20 \mathrm{a}$ & $0.56 \mathrm{bc}$ & $17.53 \mathrm{a}$ & $0.37 \mathrm{~b}$ \\
\hline 12 & 61 & $10.55 \mathrm{a}$ & $7.26 \mathrm{ab}$ & $11.08 \mathrm{~b}$ & $0.61 \mathrm{c}$ & $28.36 \mathrm{~b}$ & $0.44 \mathrm{~b}$ \\
\hline 24 & 61 & $14.70 \mathrm{c}$ & $12.99 \mathrm{~d}$ & $9.53 \mathrm{ab}$ & $0.42 \mathrm{a}$ & $25.76 \mathrm{~b}$ & $0.22 \mathrm{a}$ \\
\hline 24 & 35 & & & & & & \\
\hline 8 & 26 & $12.54 \mathrm{~b}$ & $10.23 \mathrm{c}$ & $7.36 \mathrm{a}$ & $0.41 \mathrm{a}$ & $20.34 \mathrm{a}$ & $0.21 \mathrm{a}$ \\
\hline 24 & 35 & & & & & & \\
\hline 12 & 26 & $13.24 \mathrm{bc}$ & $9.58 \mathrm{~b}$ & $8.42 \mathrm{ab}$ & $0.47 \mathrm{ab}$ & $22.44 \mathrm{ab}$ & $0.25 \mathrm{a}$ \\
\hline 24 & 49 & & & & & & \\
\hline 8 & 12 & $13.38 \mathrm{bc}$ & $9.89 \mathrm{c}$ & $8.36 \mathrm{ab}$ & $0.45 \mathrm{a}$ & $21.92 \mathrm{ab}$ & $0.24 \mathrm{a}$ \\
\hline 24 & 49 & & & & & & \\
\hline 12 & 12 & $14.07 \mathrm{bc}$ & $10.53 \mathrm{c}$ & $8.24 \mathrm{a}$ & $0.44 \mathrm{a}$ & $23.30 \mathrm{ab}$ & $0.23 \mathrm{a}$ \\
\hline
\end{tabular}

${ }^{\mathrm{z}} \mathrm{SHI}: \mathrm{g}$ edible dry biomass/g total shoot dry biomass.

${ }^{y}$ EYR: g grain $/ \mathrm{m}^{2} /$ day.

${ }^{x}$ YER: g grain $/ \mathrm{m}^{3}$ shoot $/ \mathrm{d} / \mathrm{g}$ inedible shoot mass.

wMean separation within columns by Tukey's w procedure, $P=0.05$. 
hypothesized that increasing the daily dosage of $P A R$ early in a cropping cycle would increase dry-matter accumulation in tillers and panicles, which later would be transferred to maturing grains. In the greenhouse, $P A R$ enhancement can be accomplished by extending natural photoperiods with sufficient $P P F$ from high-intensity discharge lamps.

Continuous irradiation throughout crop production increased EYR relative to that of plants shifted after 35 or 42 d to 8 -h photoperiods, but inedible biomass production was so great that SHI and YER were second lowest for the 24-h controls. This trend continued as the time of exposure to continuous light increased before transfer to 8- or 12-h photoperiods. Control plants on continuous 8 $\mathrm{h}$ photoperiods tillered the least of all treatments, so inedible biomass production was kept in check and early-initiated tillers and their panicles had little competition during development. This, in turn, enhanced SHI and YER, but absolute grain yield and EYR were lower than for any other treatment. Photoperiods of $8 \mathrm{~h}$ limited daily $P P F$ to the extent that edible yield was sacrificed. For the 12-h controls, however, tillering was not so extensive as to tax the plants' assimilate reserves during grainfill, yet was not so limited as to jeopardize grain yield. Of all treatments tested, the 12-h control plants produced the highest EYR, YER, and SHI, yet had a similar number of tillers as the 8-h controls.

Studies examining the efficiency of cropping protocols for ALS ultimately must include data on yield of edible and inedible biomass produced, cropping time and volume occupied, as well as energy utilized (Salisbury and Bugbee, 1988). All of these parameters, except energy utilized, are incorporated into YER. The YER values obtained in this study indicate that 'Ai-Nan-Tsao' rice is more productive if grown under a 12-h than an 8- or 24$\mathrm{h}$ photoperiod for the entire cropping cycle, or if exposed to continuous light for 35 to $42 \mathrm{~d}$ before shifting to an 8- or 12-h photoperiod. The reciprocal of this experiment, i.e., growing 'Ai-Nan-Tsao' rice under different numbers of days with 8-h photoperiods before transfer to continuous light, also indicated that continuous light does not benefit rice yield or productivity if given later in the cropping cycle (Volk and Mitchell, 1995).

If providing natural sunlight to the plantgrowth modules of a space-deployed ALS via light piping or fiber optics is not possible or practical, then $P A R$ must be provided by electric lamps. In an artificial lighting scenario, the shortest photoperiod that doesn't lower yield or lengthen time to harvest is preferred, because less overall energy will be expended (Salisbury and Bugbee, 1988). The use of 12$\mathrm{h}$ photoperiods for day-neutral rice is attractive because it used fewer kilowatt-hours of electrical energy for plant-growth lighting than any other treatment tested in this study except the 8-h controls. However, this also means fewer hours of photosynthesis, the oxygenevolving and carbon dioxide-absorbing process that will revitalize atmosphere in a closed, space-deployed ALS (Galston, 1994). Future studies growing 'Ai-Nan-Tsao' rice hydroponically under optimizing controlled environments will determine if 12 -h photoperiods provide the best trade-off for ALS in terms of energy utilization vs. life-support requirements of human crews.

\section{Literature Cited}

Corey, K.A. and R.M. Wheeler 1992. Gas exchange in NASA's biomass production chamber. BioScience 42:503-509.

Fagade, S.O. and S.K. DeDatta 1971. Leaf area index, tillering capacity, and grain yield of tropical rice as affected by plant density and nitrogen level. Agron. J. 63:503-506.

Galston, A.W. 1994. Ecology from space. Environ. Sci. Technol. 28:250A
Gravois, K.A. and R.S. Helms. 1992. Path analysis of rice yield and yield components as affected by seeding rate. Agron. J. 84:1-4.

Green, C.F. 1984. Discriminants of productivity in small grain cereals: A review. J. Natl. Inst. Bot. 16:453-463.

Hoff, J.E., J.M. Howe, and C.A. Mitchell 1982. Nutritional and cultural aspects of plant species selection for a regenerative life support system. NASA Contractor Rpt. 166324.

Janardhan, K.V. and K.S. Murty. 1979. Effect of low light during vegetative stage on photosynthesis and growth attributes in rice. Indian J. Plant Physiol. 21:156-162.

Janardhan K.V., K.S. Murty, and N.B. Dash. 1979. Effect of low light during ripening period on grain yield and translocation of assimilates in rice varieties. Indian J. Plant Physiol. 23:163168.

Mitchell, C.A. 1994. Bioregenerative life-support systems. Amer. J. Clin. Nutr. 60:820S-824S.

Nayak, S.K. and K.S. Murty 1980. Effect of varying light intensities on yield and growth parameters in rice. Indian J. Plant Physiol. 23:309-316.

Olson, R.L., M.W. Oleson, and T.J. Slavin. 1988. ALS for advanced manned missions. HortScience 23:275-286.

Salisbury, F. and B. Bugbee. 1988. Plant productivity in controlled environments. HortScience 23:293-299.

Schwartzkopf, S.H. 1992. Design of a controlled ecological life support system. BioScience 42:526-535.

Vergara, B., T. Chang, and R. Lilis. 1969. The flowering response of the rice plant to photoperiod. Bul. 8, Intl. Rice Res. Inst., Los Banos, Laguna, Philippines.

Volk, G.M. and C.A. Mitchell. 1995. Photoperiod shift effects on yield characteristics of rice. Crop Sci. 35:1631-1635.

Wallace, D.H., R.W. Zobel, and K.S. Yourstone. 1993. A whole-system reconsideration of paradigms about photoperiod and temperature control of crop yield. J. Theor. Appl. Genet. 86:1726.

Wheeler, R.M. and T.W. Tibbitts. 1986. Utilization of potatoes for life support systems in space. I. Cultivar-photoperiod interactions. Amer. Potato J. 63:315-323. 